\title{
Dried Blood Spots Collected on Filter Paper: An International Resource for the Diagnosis and Genetic Characterization of Human Immunodeficiency Virus Type-1
}

\author{
Sharon A Cassol*/+, Stanley Read**, Bruce G Weniger***, Perry Gomez****, \\ Normand Lapointe****, Chin-Yih Ou***, P George Babu******
}

British Columbia Centre for Excellence in HIV/AIDS, Saint Paul's Hospital, 1081 Burrard Street, Vancouver, British Columbia, Canada, V6Z 1Y6 *Department of Pathology and Laboratory Medicine, the University of British Columbia, Vancouver, British Columbia, Canada **Department of Pediatrics, Hospital for Sick Children, Toronto, Ontario, Canada ***Division of HIV/AIDS, Centers for Disease Control and Prevention, Atlanta, Georgia, USA ****Princess Margaret Hospital, Nassau, Bahamas, *****Hôpital Sainte-Justine, Montreal, Quebec, Canada $* * * * * *$ Christian Medical College Hospital, Vellore, India

The collection of dried blood spots (DBS) on filter paper provides a powerful approach for the development of large-scale, population-based screening programs. DBS methods are particularly valuable in developing countries and isolated rural regions where resources are limited. Large numbers of field specimens can be economically collected and shipped to centralized reference laboratories for genetic and (or) serological analysis. Alternatively, the dried blood can be stored and used as an archival resource to rapidly establish the frequency and distribution of newly recognized mutations, confirm patient identity or track the origins and emergence of newly identified pathogens. In this report, we describe how PCR-based technologies are beginning to interface with international screening programmes for the diagnosis and genetic characterization of human immunodeficiency virus type 1 (HIV-1). In particular, we review recent progress using DBS specimens to resolve the HIV-1 infection status of neonates, monitor the genetic evolution of HIV-1 during early infancy and establish a sentinel surveillance system for the systematic monitoring of HIV-1 genetic variation in Asia.

Key words: HIV-1 - dried blood - diagnosis - genetic variation - vaccines

\section{EVOLUTION OF DBS METHODOLOGY}

Since their introduction for the diagnosis of phenylketonuria (Guthrie \& Susi 1963), dried blood spots, commonly known as Guthrie spots, have been widely used in more than 50 countries for neonatal screening of a broad range of metabolic and genetic disorders including, the hemoglobinopathies (Garrick et al. 1973), hypothryroidism (Maeda et al. 1985) and Duchenne muscular dystrophy (McCabe et al. 1990). In the HIV-1 setting, neonatal blood spots were initially used for antibody testing to determine the seroprevalence of HIV-1 infection in pregnant women (Hoff et al. 1988). Subsequently, it was demonstrated that DNA extracted from dried blood was suitable for the diagnosis of HIV-1 by the polymerase chain reaction (PCR) (Cassol et al. 1991).

\footnotetext{
Funded by the Province of British Columbia and the British Columbia Centre for Excellence in HIV/AIDS ${ }^{+}$Corresponding author. Fax:1-604-631.5464 - e-mail: cassol@hivnet.ubc.ca

Received 7 December 1995

Accepted 10 January 1996
}

The first HIV-1 PCR applications of dried blood spots (DBS) involved lengthy organic extraction, followed by DNA precipitation, amplification and solution hybridization with radiolabeled probes (Cassol et al. 1991, 1992a). Although these assays were sensitive and specific, they were tedious and time consuming, involved the use of isotopes and sometimes lead to inadvertent loss of the DNA. For these reasons, the technology was most useful in research settings (Comeau et al. 1992, Yourno et al. 1992, 1993, Nyambi et al. 1994). Recently, in collaboration with Drs Ann Butcher and Joanne Spadoro, we have been able to adapt DBS PCR to a standardized, commercially available microwell plate amplification and detection kit, Amplicor HIV-1 produced by Roche Molecular Systems (Somerville, NJ, USA) (Cassol et al. 1994). The microwell assay is rapid, involves minimal sample manipulation and uses equipment (ELISA reader and plate washer) that is readily available in most laboratories. These features render the assay suitable for use in routine clinical and public health settings.

In microwell method, circles of dried blood ( 0.6 $\mathrm{cm}$ in diameter) are excised from the filter, transferred to a $1.5 \mathrm{ml}$ screw-cap tube and incubated 
with $1.0 \mathrm{ml}$ of Specimen Wash Buffer (Roche) for $30 \mathrm{~min}$ at $20^{\circ} \mathrm{C}$ on an Eppendorf 5436 Thermomixer at 1,000 revolution/min. The hemoglobin-containing supernatant is then removed by aspiration and the DNA is eluted by heating the filter at $95^{\circ} \mathrm{C}$ in $100 \mu \mathrm{l}$ of $5 \%$ Chelex (BioRad) for $1 \mathrm{hr}$. Following centrifugation (1 min at 12,000 x g), $50 \mu \mathrm{l}$ aliquots of the Chelex supernatant are amplified on a Perkin-Elmer TC9600 thermocycler in a $100 \mu \mathrm{l}$ reaction volume containing dATP, dCTP, dGTP, dUTP, AmpErase, AmpliTaq, salts and biotinylated primers (Bio-SK431 and BioSK462)(Amplicor HIV-1 kit). The PCR product is denatured, hybridized to individual wells of a 96well microwell plate coated with SK102 and detected colorimetrically using avidin-horseradish peroxidase conjugate and the chromogen, tetramethylbenzidine (Cassol et al. 1994).

In addition to diagnosis, another recent development has been the scale-up and use of DBS for HIV-1 sequence analysis (Cassol et al. 1993). In this method, the DNA is eluted into Chelex, amplified in a "nested" or two-step PCR reaction and sequenced directly using a Taq Dye Dideoxy ${ }^{\mathrm{TM}}$ Cycle Sequencing Kit (Applied Biosystems). Data for the forward and reverse strands is collected on a 373A DNA Sequencer and assembled using SeqEd software. A typical protocol for sequencing of the immunologically important $\mathrm{C} 2 \mathrm{~V} 3$ region of the HIV-1 envelope gene is shown below. Primer sequences and map locations (numbered according to the sequence of HIV-1 LAI, GenBank accession no. K02013) are shown in Table I.

\section{APPLICATIONS OF DBS TO NEONATAL SCREENING PROGRAMS}

Early diagnosis of perinatal HIV-1 transmission - Over the past few years, early diagnosis combined with antivirial treatment and prophylaxis against Pneumocystis carinii pneumonia, has significantly reduced morbidity and improved the quality of life for many HIV-1 infected infants. Since maternal antibodies preclude the serological diagnosis of HIV-1 in the newborn period, most diagnoses are based on virus isolation or PCR. Both of these technologies are highly specialized, ex- pensive and inadequate for large-scale perinatal testing. The collection of small amounts of whole blood on filter paper is inexpensive and offers a logistically simple approach for the collection, storage and shipment of large numbers of neonatal samples.

To date, we have performed more than 1014 diagnostic tests on 507 coded filter papers collected from 196 infants participating in ongoing prospective studies of perinatal HIV-1 transmission in Canada and the Bahamas. Infants were diagnosed with HIV-1 infection if two or more specimens tested culture, PCR or p24 antigen positive and HIV-1 negative, if at 18 months of age, all cultures, PCR and serological tests were negative and the child was healthy with a normal CD4+ count. HIV-1 DNA was detected in 177 of 187 DBS collected from 56 infants with documented HIV-1 infection giving the assay, in this cohort, an overall sensitivity of $94.7 \%$. No HIV-1 was detected in 320 DBS collected from 140 uninfected infants to give a specificity of $100 \%$. When the infected infants were stratified according to age, HIV-1 was detected in 3 of $11(27 \%)$ DBS collected during the first 4 days of life, in 8 of 9 (89\%) DBS collected between days 10 and 15, and in $99.4 \%$ of 167 DBS collected after 15 days of life. This level of sensitivity and specificity is comparable to that attained using conventional PCR methods (Dunn et al. 1995). Table II is representative of DBS PCR testing in the neonatal period.

The failure to detect HIV-1 in all infants at birth has been noted previously and may be related to the timing and mode of transmission. As a working definition, it has been suggested that those infants who test PCR positive at birth, may have acquired their infections in utero, while those infants who test negative at birth and positive by 15 to 30 days of life, may have become infected during labor and delivery. In an attempt to improve the sensitivity of DBS PCR in the interval immediately after birth, we are investigating the feasibility of amplifying viral RNA, in addition to proviral DNA.

A low proviral burden at birth, suggests that early treatment and (or) intervention will be effective in preventing the establishment, or reducing

TABLE I

Frequently used oligonucleotide primers

\begin{tabular}{lllr}
\hline PCR Primer & Orientation & Sequence $\left(5^{\prime}-3^{\prime}\right)$ & Location \\
\hline Outer MK603-F & & CAGAAAAATTGTGGGTCACAGTCTATTATGGGGTACCT & $89-126$ \\
Outer CD4XBO-R2 & & gttctcgagTATAATTCACTTITCCAATTGTCC & $1426-1439$ \\
Inner MK650iF & - & AATGTCAGCACAGTACAATGTACAC & $715-739$ \\
Inner V2iF & - & GCATGAGGATATAATCAGTTTATGGGAT & $309-336$ \\
Inner V3iR & - & ACAATTTCTGGGTCCCCTCCTGAGGA & $1078-1103$ \\
\hline
\end{tabular}


TABLE II

HIV-1 detection in infected newborns over time

\begin{tabular}{cccc}
\hline Infant no. & Age & \multicolumn{2}{c}{$\begin{array}{c}\text { Result after amplification } \\
\text { reaction }\end{array}$} \\
\cline { 3 - 4 } & & 1 & 2 \\
\hline \multirow{2}{*}{1} & $24 \mathrm{hr}$ & - & - \\
& 3 days & - & - \\
& 15 days & + & + \\
& 30 days & + & + \\
& 6 mo & + & + \\
2 & $24 \mathrm{hr}$ & - & - \\
& $2 \mathrm{mo}$ & + & + \\
& $4 \mathrm{mo}$ & + & + \\
& 6 mo & + & + \\
& $9 \mathrm{mo}$ & + & + \\
3 & $12 \mathrm{mo}$ & + & + \\
& $24 \mathrm{hr}$ & + & + \\
& 13 days & + & + \\
& 2 days & + & + \\
& 11 days & + & + \\
& 30 days & + & + \\
\hline
\end{tabular}

the severity of perinatal infection. This interpretation is consistent with the recent ACTG study 076 (Connor et al. 1994), showing that administration of zidovudine (ZDV) to the mother during the second to third trimester of pregnancy, during labor and delivery and, to the infant, during the first 6 weeks of life, results in a $68 \%$ decrease in neonatal infection, presumably by reducing the viral burden in the mother and (or) the newborn. Current efforts in our laboratory are focused on adapting DBS PCR to a quantitative format for measuring the effects of therapy on viral burden and transmission.

Screening for $Z D V$ resistant mutations - Despite the substantial benefit of ZDV, there are still many unknowns relating to the use antivirals during pregnancy. In particular, there is concern that antiviral administration, especially if given early in the course of gestation, might lead to the emergence of drug resistant virus, which could then be transmitted to the infant. Again, as shown in Fig. 1 , dried blood appears to be useful for the rapid identification of mothers and infants with significant levels ( $>10 \%)$ of resistance mutations. Using this approach, all five known ZDV-associated mutations (reverse transcriptase (RT) gene codons: M41L, D67G, K70R, T215Y/F and K219Q) can be semi-quantitatively detected using two different sequencing reactions. A two-base change (ACC to TAC of TTC) at amino acid 215 (RT T215Y/F), appears to be most common mutation and may serve as the best in vivo marker of high-level ZDV
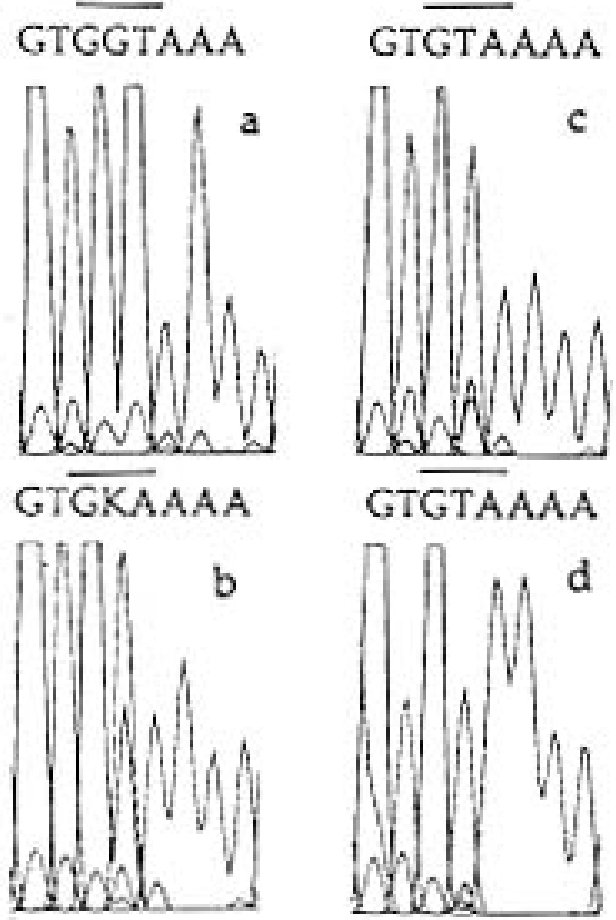

Fig. 1: semi-quantitative detection of HIV-1 drug-resistance mutations by automated sequencing of DBS specimens. a-d, represent DNA sequence chromatograms of RT codon 215 obtained from an HIV-1 infected infant pre-treatment (a), and at four (b), seven (c) and nine (d) months following initiation of ZDV therapy. Sequences shown were obtained from, and therefore are presented as, the minus (non-coding) strand. The minus-strand GGT, GKA and GTA sequences shown, correspond to the plus-strand codons ACC (Thr), TMC [a mixture of TCC/TAC (Ser/Tyr)] and TAC (Tyr), respectively. Prior to therapy, all codons within the amino-terminal half of the RT gene were wild-type, including the RT 215 codon that is associated with high-level ZDV resistance. After 4 months of ZDV therapy, the 215 codon had evolved into a mixture of two different mutants and, by 9 months, the wild-type virus population was completely replaced with the drug resistant codon TAC (Tyr).

resistance (Kozal et al. 1993, Holodniy et al. 1995). In mothers who develop 215 mutations, it may be advisable to switch to an alternative therapy.

Surveillance monitoring - In addition to diagnosis and follow-up of individual infants, DBS PCR should facilitate large-scale surveillance monitoring, especially if incorporated into established cohort studies. Infants who test DBS positive for the presence of maternal antibodies could be retested by PCR, at 15 days and one month of age, to determine their true infection status. The establishment of a sentinel surveillance system with regular, unbiased sampling is the only way to accurately monitor local changes in the emerging pediatric pandemic and obtain a baseline for evaluating preventive strategies and intervention programs. 
Genetic characterization of HIV-1 variants transmitted from mother-to-child - To date, most HIV-1 sequencing efforts have focused on the hypervariable domain (V3) of the HIV-1 envelope protein which serves as the principal epitope for type-specific neutralization antibodies (Myers et al. 1993). An understanding of this region may be important not only for vaccine development, but also, to better understand the adaptive responses made by HIV-1 to evade the immune system. The V3 region may also play an important role in viral pathogenesis, cellular tropism and perinatal transmission (Kuiken et al. 1992).

Comparative analysis of V3 sequences derived from mother-infant pairs has shown that the transmitted variant(s) is epidemiologically linked to the mother's viral sequences, but that it is more homogeneous and often represents a minor quasispecies of the mother's total virus population (Wolinsky et al. 1992, Ahmad et al. 1995, Briant et al. 1995). With time, the transmitted sequence(s) usually diversifies, presumably as a result of selective pressure in the infant. Although informative, these studies were performed on small numbers of children, born to mothers infected with subtype B virus of the "classical" or North American genotype.

The ability to sequence the $\mathrm{C} 2 \mathrm{~V} 3$ region directly from DBS specimens, would allow for the characterization of large numbers of variants involved in maternal-child transmission. Using this approach, we have sequenced more than 58 DBS serially collected from 19 HIV-1 infected Canadian and Bahamian infants. The transmitted "consensus" sequence(s) appeared homogeneous and, with one exception, had a highly conserved $\mathrm{N}$-glycosylation site proximal to the first cysteine of the V3 loop. Although each infant's sequences were unique, sequences amplified from Bahamian infants were particularly divergent and carried a large number of amino acid substitutions at the tip of the V3 loop (Table III). The GPGR tetramer, that is characteristic of most North American isolates, was detected in only 2 of 10 Bahamian specimens (manuscript in preparation). When studied over time, some infants showed little or no variation in their $\mathrm{C} 2 \mathrm{~V} 3$ "consensus" sequence during the first two years of life while, other infants displayed multiple synonymous and non-synonymous mutations in both the V3 loop and the adjacent flanking regions (Fig. 2). Ongoing studies are designed to correlate increasing heterogeneity (or lack of heterogeneity) in infant sequence sets with changes in the infant's clinical and immunological status, and with differences in the phenotypic properties of the virus. In particular, it will be important to determine whether a more efficacious immune response is associated with increasing genetic diversity and whether the transmitted viral variant represents a minor quasispecies that has escaped immune surveillance.
TABLE III

Summary of variations found at the hexameric tip of the V3 loop

\begin{tabular}{|c|c|c|c|c|}
\hline & \multicolumn{3}{|c|}{ Subtype } & \multirow[t]{2}{*}{ Country } \\
\hline & A & B & $\mathrm{C}$ & \\
\hline GPGQTF & & & 25 & India \\
\hline GPGQTF & 2 & & & India \\
\hline GPGQAW & & $5^{a}$ & & Myanmar \\
\hline GPGQAI & 1 & & & Canada (Africa) ${ }^{b}$ \\
\hline GPGRAF & & 21 & & Canada \\
\hline APGRAF & & 1 & & Canada \\
\hline GPGRAV & & 3 & & Canada \\
\hline GPGGAF & & 2 & & Canada \\
\hline GPGRAF & & 2 & & Bahamas \\
\hline GPGKAF & & 3 & & Bahamas \\
\hline GPGRAW & & 1 & & Bahamas \\
\hline GPGQAF & & 1 & & Bahamas \\
\hline GPGKVF & & 1 & & Bahamas \\
\hline GFGRAL & & 1 & & Bahamas \\
\hline
\end{tabular}

$a$ : subtype B from Myannar was of the Thai genotype (subtype $\mathrm{B}_{\mathrm{B}}$ )

$b$ : this specimen came from an infant born in Montreal to a Women from Africa.

Table III: summary of amino acid variations found at the hexameric tip of the V3 loop of 51 DBS specimens collected from 19 Canadian and Bahamian infants, and 32 adult patients from India and Myanmar. The GPGR tetrapeptide predominates in continental North America and Western Europe, while GPGQ is common in Asia. This tetrapeptide, is the principal determinant responsible for eliciting neutralizing antibodies. Amino acid changes adjacent to the tetramer can alter the specificity of these antibodies. Sequences derived from Bahamian infant specimens displayed a wide-range of amino acid substitutions in both the GPGR tip and in positions immediately proximal to the tip. These findings may have important implications for vaccine design.

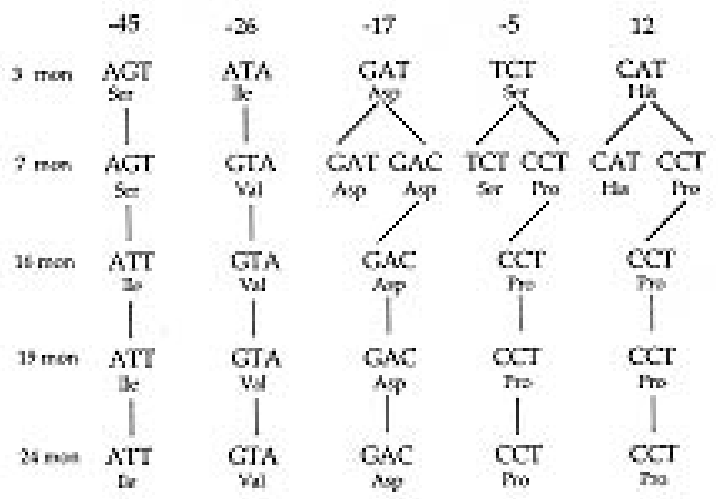

Fig. 2: changes in nucleotide and amino acid patterns of a Bahamian infant sampled longitudinally. A total of five nucleotide changes, leading to four non-synonymous and one synonymous change, were observed over a period of 21 months. A mixture of wild-type and mutant sequences preceded the final fixation of mutations at positions $-17,-5$ and +12 . Numbering is relative to the V3 loop, with position 1 representing the amino acid immediately downstream from the first cysteine residue. 


\section{APPLICATION OF DBS TO THE MONITORING OF HIV-1 GLOBAL VARIATION}

Frequency and distribution of HIV-1 subtypes Systematic collection and analysis of HIV-1 genetic variants from different epicenters of the HIV-1/ AIDS pandemic is a critical step in the development of a globally effective vaccine. To date, at least 8 HIV-1 subtypes (A through $\mathrm{G}$, and $\mathrm{O}$ ) have been identified based on genetic differences in the viral envelope gene. An understanding of the geographic and risk group associations of these subtypes is just beginning to emerge, with early data suggesting continued progressive intermixing of subtypes, both within and between continents. Subtype B, initially found in North America and Europe, has now been recovered from all five continents. Subtypes A, C and D are common in Africa (Myers et al. 1993), with subtype $\mathrm{C}$ also being found in India (Tsuchie et al. 1993, Rubsamen-Waigmann 1994) and Malaysia (Weniger et al. 1994). Subtype E, which is characteristic of the heterosexual epidemic in Thailand (McCutchan et al. 1992, Ou et al. 1993, Pau et al. 1993, Weniger et al. 1994) is also present in the Central African Republic. The newly recognized subtype F has been detected in Romania (Dumitrescu et al 1994) and Brazil (Morgado et al. 1994, GalvãoCastro, manuscript submitted). These sequence sets were collected from a limited number of different geographic locales, and the full range and distribution of global variants remains to be established, especially in large areas of Asia, Africa and South America where sample collection has been difficult.

The ability to use DBS specimens for HIV-1 sequence analysis provides a new resource for the systematic collection of international sequence data. To date, we have identified four HIV-1 subtypes, with a partial segregation according to geographic origins and mode of transmission, among 42 DBS specimens collected in 1992 from five different countries in Asia (manuscript submitted). Subtype $\mathrm{C}$ predominated in the Vellore region of southeast India and was detected in $100 \%$ of 25 patients with presumed heterosexual infection, while subtype A was detected in two homosexuals from the same region. Subtype E was identified in filter paper specimens from two heterosexual patients, one each from Thailand and Myanmar, and in one injecting drug user (IDU) from Thailand. The remaining specimens, collected primarily from IDUs and homosexual patients in Thailand, Myanmar, China and Indonesia, fell within subtype B and had either the "classical" North American sequence, or the Thai genotype (subtype $\mathrm{B}_{\mathrm{B}}$ ) characterized by a highly distinctive ihLgpg $\mathbf{Q} \mathrm{W}$ Wyttg $\mathbf{Q}$ signature sequence at the tip of the V3 loop. Six specimens, classified as non-reactive by serology (Pau et al. 1993, Sherefa et al. 1994) were resolved by sequencing. All of these findings are consistent with the known epidemiology of HIV-1 in Asia (Ou et al. 1993, Jain et al. 1993, John et al. 1993, Weniger et al. 1994, Shao et al. 1994) and suggest that, in addition to screening, DBS sequencing will be particularly useful for the resolution of indeterminate or non-reactive serotypes and the fine genetic characterization of HIV-1 subtypes defined by the heteroduplex mobility assay (HMA)(Delwart et al. 1993, Bachmann et al. 1994). A better understanding of global sequence variation is important, not only to track the spread of HIV1 between continents, but also, to monitor the emergence of new variants with increased virulence, identify subtypes of HIV-1 that are easily transmitted between individuals and ensure that vaccines are developed against contemporary, biologically-important variants that are prevalent within specific communities (Esparza et al. 1991, Vermund et al. 1993). In the event that vaccination is less than $100 \%$ effective, sequencing will be required to identify the "break-through" strains.

\section{FUTURE DEVELOPMENT OF DBS TECHNOL- OGY}

Although these efforts represent a good starting point, large-scale applications of HIV-1 DBS techology will require further refinements, including intensive standardization, optimization and increased automation. In the future, largely as a result of the intense effort being put into the Human Genome Initiative, it should be possible to increase the throughput of DBS PCR and DBS sequencing by interfacing these methods with robotic workstations such as the Catalyst Molecular Biology Lab Station from Applied Biosystems. Hopefully, increased standardization and automation will also lead to significant cost reductions, making it economically feasible to conduct large-scale prevalence testing in developing countries where the pandemic is most severe. As in all PCR-based technologies, great care must be taken to avoid carryover contamination and false-positive results (Kwok 1990).

\section{DIRECT AUTOMATED SEQUENCING HIV-1 FIELD ISOLATES FROM DRIED BLOOD COL- LECTED ON FILTER PAPER}

1. Collect blood by venipuncture and apply approximately $2 \mathrm{ml}$ to the back of a no. 9 Schleicher and Schuell newborn blotter in a dropwise fashion. Air dry $3 \mathrm{hr}$ and place each filter in an individual envelope for storage or shipment.

2. At the time of analysis, excise two $1 \mathrm{~cm}^{2}$ circles of dried blood with sterile scissors, cut in half and place each half into a $1.5-\mathrm{ml}$ sterile microfuge tube.

3. Add $1.4 \mathrm{ml}$ of Specimen Wash Buffer (Roche) and incubate $30 \mathrm{~min}$ at $20^{\circ} \mathrm{C}$ on an Eppendorf 
Thermomixer ${ }^{\mathrm{TM}}$ set at 1,000 revolutions/min.

4. Remove hemoglobin-containing supernatant by aspiration. Add $200 \mu \mathrm{l}$ of $5 \%$ Chelex and heat at $95^{\circ} \mathrm{C}$ for 1 $\mathrm{hr}$ on Thermomixer (1,000 revolutions/min).

5. Centrifuge (12,000 rpm, $5 \mathrm{~min})$, collect and pool supernatants. Concentrate four-fold using a Centricon concentrator (Amicon Inc, Beverly, MA, USA).

6. Add $12.5 \mu \mathrm{l}$ of concentrate to a standard PCR reaction. Amplify using a two-step, nested protocol.

7. Separate PCR product on $2 \%$ agarose (Nusieve, Pharmacia). Excise product band and purify using a QIA Quick Gel Extraction kit (Quiagen, CA, USA).

8. Sequence directly using a Taq Dye Dideoxy ${ }^{\mathrm{TM}}$ Cycle Sequencing Kit (Applied Biosystems, CA, USA). Remove excess dye on a Centri-Sep spin column (Princeton Separations, NJ, USA).

9. Electrophoresis $10 \mathrm{hr}$ on a 373A Fluorescent DNA Sequencer (Applied Bio-systems). Edit and assemble data for both strands.

10. Align, analyze and construct phylogenetic trees using programs CLUSTALV (Higgins et al. 1992), neighbor joining, SEQBOOT and DNAML from the 3.53c version of the PHYLIP software (Felsenstein 1993) using GDE (version 2.0, Harvard Genome Laboratory, Boston) as a user interface.

\section{ACKNOWLEDGEMENTS}

To Carol Major (Ontario Ministry of Health, Toronto, Ontario); Micheline Fauvel (le Laboratoire de Santé Publique du Quebec); Bernardo Galvão-Castro (Laboratório Avançado de Saúde Pública, Centro de Pesquisa Gonçalo Moniz, Fundação Oswaldo Cruz, Salvador, Brasil); Myo Thet Htoon (Myanmar Department of Health); Zheng Xiwen (Chinese Academy of Preventive Medicine, Beijing), Gerald Jennings (US Army, Fort Detrick, MD); Nancy L Young (HIV/AIDS Collaboration, Bangkok, Thailand) for their ongoing collaboration, advice and support, and to Tidiane Sy, Barbara Leung, Theresa Mo and Arusha Oloumi (BC Centre for Excellence in HIV/AIDS) for their co-operation and expertise in laboratory investigations.

\section{REFERENCES}

Ahmad N, Baroudy BM, Baker R, Chappey C 1995. Genetic analysis of human immunodeficiency virus type 1 envelope V3 region isolates from mothers and infants after perinatal transmission. J Virol 69: 1001-1012.

Bachmann MH, Delwart EI, Shpaer EG, Longenfelter P, Singal R, Mullins JI 1994. Rapid genetic characterization of HIV type 1 strains from four World Health Organization-sponsored vaccine evaluation sites using a heteroduplex mobility assay. AIDS Res Hum Retroviruses 10: 1345-1353.

Briant L, Wade CM, Puel J, Leigh Brown AJ, Guyader M 1995. Analysis of envelope sequence variants suggests multiple mechanisms of mother-to-child transmission of human immunodeficiency virus type 1. J Virol 69: 3778-3788.

Cassol S, Salas T, Arella M, Neumann P, Schechter MT, O'Shaughnessy M 1991. Use of dried blood spot specimens in the detection of human immunodefi- ciency virus type I by the polymerase chain reaction. J Clin Microbiol 29: 667-671.

Cassol S, Lapointe N, Salas T, Hankins C, Arella M, Fauvel M, Delage G, Boucher M, Samson J, Charest J, Montpetit ML, O’Shaughnessy MV 1992a. Diagnosis of vertical HIV-1 transmission using the polymerase chain reaction and dried blood spot specimens. J Acquir Imm Defic Syndr 5: 113-119.

Cassol S, Salas T, Gill MJ, Montpetit M, Rudnik J, Sy TC, O’Shaughnessy M 1992b. Stability of dried blood spot specimens for detection of human immunodeficiency virus DNA by polymerase chain reaction. J Clin Microbiol 30: 3039-3042.

Cassol S, Estable M, Merzouki A, Montaner J, Sy T, Read S, Arella M, Butcher A, Kinard S, O'Shaughnessy M 1993. Monitoring genetic variation in HIV-1 field strains by direct sequencing of dried blood spot specimens: Implications for vaccine development. Huitième Colloque des Cent Gardes, Paris, 75-78.

Cassol S, Butcher A, Kinard S, Spadoro J, Sy T, Lapointe N, Read S, Gomez P, Fauvel M, Major C, O'Shaughnessy M 1994. Rapid screening for early detection of mother-to-child transmission of human immunodeficiency virus type 1. J Clin Microbiol 32:2641-2645.

Comeau AM, Hsu HW, Schwerzler M, Mushinsky G, Grady GF 1992. Detection of HIV in specimens from newborn screeening programs. N Engl J Med 326: 1703.

Connor EM, Sperling RS, Gelber R, Kiselev P, Scott G, O’Sullivan MJ, Van Dyke R, Bey M, Shearer W, Jacobson RL, Jimenez E, O'Neill E, Bazin B, Delfraissy JF, Culnane M, Coombs R, Elkins M, Maje J, Stratton P, Balsley J, and the Pediatric AIDS Clinical Trials Group Protocol 076 Study Group, 1994. Reduction of maternal-infant transmission of human immunodeficiency virus type 1 with zidovudine treatment. N Engl J Med 331: 1173-1180.

Delwart EL, Shpaer EG, Louwagie J, McCutchan FE, Grez M, Rubsamen-Waigmann, Mullins JI 1993. Genetic relationships determined by a DNA heteroduplex mobility assay: analysis of HIV-1 env genes. Science 262: 1257-1261.

Dimitrescu O, Kalish ML, Kliks SC, Bandea CI, Levy JA 1994. Characterization of human immunodeficiency virus type 1 isolates from children in Romania: identification of a new envelope subtype. $J$ Infect Dis 169: 281-288.

Dunn DT, Brandt CD, Krivine A, Cassol S, Roques P, Borkowsky W, De Rossi A, Denamur E, Ehrnst A, Loveday C, Harris J, McIntosh K, Comeau AM, Rakusan T, Newell M-L, Peckham CS 1995. The sensitivity of polymerase chain reaction for the detection of HIV-1 infection in neonates. AIDS 9: 7-11.

Esparza J, Osmanov S, Kallings L, Wigzell H 1991. Planning for HIV vaccine trials: The World Health Organization perspective. AIDS 5 (suppl 2): S159S163.

Felsenstein J. PHYLIP (Phylogeny Inference Package) Version 3.5c. Distributed by J. Felsenstein. Seattle: Department of Genetics, University of Washington, 
1993.

Galvão-Castro B, Bongertz V, Morgado M. The importance of systematicially monitoring HIV-1 polymorphism in sites where HIV-vaccines will be evaluated (submitted).

Garrick MD, Dembure BS, Guthrie R 1973. Sickle-cell anemia and other hemoglobinopathies: procedures and strategy for screening employing spots of blood on filter paper as specimens. N Engl J Med 288: 1256-1268.

Guthrie R, Susi A 1963. A simple phenylalanine method for detecting phenylketonuria in large populations of newborn infants. Pediatrics 32: 338-343.

Higgins DB, Bleasby AJ, Fuchs R 1992. CLUSTALV: improved softward from multiple sequence alignment. CABIOS 8: 189-191.

Hoff R, Berarde VP, Weiblen BJ, Mahoney-Trout L, Mitchell M, Grad G 1988. Seroprevalence of human immunodeficiency virus among child-bearing women. $N$ Engl J Med 318: 525-530.

Holodniy M, Mole L, Margolis D, Moss J, Dong H, Boyer E, Urdea M, Kolberg J, Eastman S 1995. Determination of human immunodeficiency virus RNA in plasma and cellular viral DNA genotypic zidovudine resistance and viral load during zidovudine-didanosine combination therapy. $J$ Virol 69: 3510-3516.

Jain MK, John TJ, Keusch GT 1994. A review of human immunodeficiency virus infection in India. AIDS 8 (suppl 2): S61-S75.

John TJ, Babu PG, Saraswathi NK, Jayakumari H, Selvaraj R, Kaur A, Chacko S, Jacob M, Ramachandran P, Tripathy SP 1993. The epidemiology of AIDS in the Vellore region, Southern India. AIDS 7: 421-424.

Kozal MJ, Shafer RW, Winters MA, Katzenstein DA, Merign TC 1993. A mutation in human immunodeficiency virus reverse transcriptase and decline in CD4 lymphocytes numbers in long-term zidovudine recipients. J Infect Dis 167: 526-532.

Kwok S 1990. Procedures to minimize PCR-product carry-over, p. 142-5. In MA Innis, SH Gelfand, JJ Sninsky and TJ White (eds), PCR protocols: a guide to methods and application. Academic Press, Inc., San Diego, CA, U.S.A.

Kuiken CL, Jong deJJ, Baan E, Keulen W, Tersmetter M, Goudsmit J 1992. Evolution of the V3 envelope domain in proviral sequences and isolated of human immunodeficiency virus type 1 during transition of virus biological phenotype. J Virol 66: 4622-7.

Maeda M, Ito K, Arakawa H, Tsuija A 1985. An enzyme-linked immunosorbent assay for thyroxine in dried blood spotted on filter paper. J Immunol Methods 82: 83-89.

McCabe ERB, Huang M, Descartes M, Zhang Y-H, Fenwick RG 1990. DNA from Guthrie spots for diagnosis of DMD by multiplex PCR. Biochem Med Metabl Biol 44: 294-295.

McCutchan FE, Hegerich PA, Brennan TP, Phanuphak P, Singharaj P, Jugsudee A, Berman PW, Gray AM, Fowler AK, Burke DS 1992. Genetic variants of HIV-1 in Thailand. AIDS Res Hum Retroviruses 8:
1887-1895.

Morgado MG, Sabino EC, Shpaer EG, Bongertz V, Brigido L, Guimaraes MD, Castilho EA, GalvãoCastro B, Mullins JI, Hendry RM, et al. 1994. V3 region polymorphisms in HIV-1 from Brazil: prevalence of subtype B strains divergent from the North American/ European prototype and detection of subtype F: AIDS Res Hum Retroviruses 10: 569-575..

Myers G, Korber B, Wain-Hobson S, Smith RF, Pavlakis GN 1993. Human Retroviruses and AIDS 1993. Los Alamos, New Mexico: Los Alamos National Laboratory, 1993.

Nyambi PN, Fransen K, DeBeenhouwer H, Chomba EN, Temmerman M, Ndinya-Achola JO, Piot P, ver der Groen G 1994. Detection of human immunodeficiency virus type-1 (HIV-1) in heel prick blood on filter paper from children born to HIV-1 seropositive mothers. J Clin Microbiol 32: 2858-60

Ou C-Y, Takebe Y, Weniger BG, Luo C-C, Kalish M, Auwanit W, Yamazaki S, Gayle HD, Young NL, Schochetman G 1993. Independent introduction of two major HIV-1 genotypes into distinct high-risk populations in Thailand. Lancet 241: 1171-1174.

Pau C-P, Lee-Thomas S, Auwanit W, George JR, Ou CY, Parekh BS, Granada TC, Holloman DL, Phillips S, Schochetman G, Young NL, Takebe Y, Gayle HD, Weniger BG 1993. Highly specific V3-peptide enzyme immunoassay for serotyping HIV-1 specimens from Thailand. AIDS 7: 337-340.

Rubasmen-Waigmann, H, Maniar J, Gerte S, Brede HD, Dietrich V, Mohambre G, Pfutzner A 1994, High proportion of HIV-2 and HIV-1/2 double-reactive sera in two Indian states, Maharashtra and Goa: first appearance of an HIV-2 epidemic along with an HIV1 epidemic outside of Africa. Zentralbl Bakteriol Mikrobiol Hyg 280: 398-402.

Shao YM, Zhao QB, Wang B, Seng Y, Wolf H 1994. Variation and evolution of HIV-1 env gene in IDUs of Ruili region in Southwest China. Chin J Virol 10: (in press).

Sherefa K, Sonnenborg A, Steinbergs J, Sallberg M 1994. Rapid grouping of HIV-1 infection in subtypes A to E by V3 peptide serotyping and its relation to sequence analysis. Biochem Biophys Res Com 205: 1658-1664.

Tsuchie H, Maniar JK, Yoshihara N, Imai M, Kurimura T, Kitamura T 1993. Sequence analysis of V3 loop region of HIV-1 strains prevalent in India. Japan $J$ Med Sci Biol 46: 95-100.

Vermund SH, Fischer RD, Hoff R, et al. 1993. Preparing of HIV vaccine efficacy trials: partnerships and challenges. AIDS Res Hum Retroviruses 9 (suppl 1): S127-S132.

Weniger BG, Takebe Y, Ou C-Y, Yamazaki S 1994. The molecular epidemiology of HIV in Asia. AIDS 8 (suppl 2): S13-S28.

Wolinsky SM, Wike CM, Korber BTM, Hutto C, Parks WP, Rosenblum LL, Kuntsman KJ, Furtado MR, Munoz IL 1992. Selective transmission of human immunodeficiency virus type-1 variants from mother to infants. Science 255: 1134-1137.

Yourno J, Conroy J 1992. A novel polymerase chain 
reaction method for detection of human immunodeficiency virus in dried blood spots on filter paper. $J$ Clin Microbiol 30: 2887-2892.

Yourno J 1993. Direct polymerase chain reaction for detection of human immunodeficiency virus in blood spot residues on filter paper after elution of antibodies: an adjunct to serological surveys for estimating vertical transmission rates among human immunodeficiency virus antibody-positive newborns. J Clin Microbiol 31: 1364-1367. 